\title{
Prostatic compensation of the vitamin D axis in African American men
}

\author{
Zachary Richards, ${ }^{1}$ Ken Batai, ${ }^{2}$ Rachael Farhat, ${ }^{1}$ Ebony Shah, ${ }^{2}$ Andrew Makowski, ${ }^{3}$ Peter H. Gann, ${ }^{1}$ \\ Rick Kittles, ${ }^{2}$ and Larisa Nonn ${ }^{1,4}$ \\ 'Department of Pathology, University of Illinois at Chicago (UIC), Chicago, Illinois, USA. ²Division of Urology, Department \\ of Surgery, University of Arizona College of Medicine, Tucson, Arizona, USA. ${ }^{3}$ Heartland Assays LLC, Ames, lowa, USA. \\ ${ }^{4}$ University of Illinois Cancer Center, Chicago, Illinois, USA.
}

BACKGROUND. African American (AA) men are disproportionately affected by both prostate cancer ( $P C a)$ and vitamin D deficiency compared with European American (EA) men. Vitamin D deficiency is linked to increased PCa aggressiveness and mortality. Therefore, it has been hypothesized that vitamin D deficiency may contribute to the PCa disparity between AA and EA men.

METHODS. We studied a cross sectional group of 60 PCa patients (AA, $n=31$; EA, $n=29$ ) who underwent radical prostatectomy. Vitamin $D$ metabolites 25 -hydroxyvitamin $D(25(\mathrm{OH}) \mathrm{D})$ and 1,25-dihydroxyvitamin $D(1,25(\mathrm{OH}), \mathrm{D})$ were measured in the serum and tissue by uHPLC-MS-MS. Tissue was laser capture microdissected, and gene expression was quantified by microarray. DNA isolated from whole blood was genotyped for West African ancestry markers and vitamin D-related SNPs.

RESULTS. Serum concentrations of $25(\mathrm{OH}) \mathrm{D}$ were lower in AAs, but concentrations of $1,25(\mathrm{OH})_{2} \mathrm{D}$ in the prostate tissue were higher compared with EAs. Expression of the vitamin $D$ receptor was higher in prostate tissue from AAs. Expression of the extracellular receptor of vitamin $D$ binding protein, $L R P 2$, was positively associated with West African ancestry and inversely associated with tissue 25(OH)D concentrations in AAs.

CONCLUSIONS. The relationships between vitamin $\mathrm{D}$ binding protein $L R P 2$ and vitamin $\mathrm{D}$ metabolites suggest that the prohormone is actively transported into the prostate, followed by intraprostatic conversion to the active hormone, rather than passive diffusion. These findings support the presence of a compensatory response in prostate tissue to vitamin $D$ deficiency in AAs and reveal a previously unknown complexity involving tissue distribution of vitamin $D$ metabolites.

FUNDING. Department of Defense Prostate Cancer Research Program Idea Award for Disparities Research PC121923 (LN and RK) and the NIH 1R01MD007105 (RK).

Conflict of interest: The authors have declared that no conflict of interest exists.

Submitted: October 12, 2016 Accepted: December 13, 2016 Published: January 26, 2017

Reference information: JCI Insight. 2017;2(2):e91054. doi:10.1172/ji.insight.91054.

\section{Introduction}

Vitamin D is an essential regulatory hormone for normal human physiology (1). The canonical role for vitamin $\mathrm{D}$ is calcium homeostasis; however, vitamin $\mathrm{D}$ deficiency has been associated with both calcium-related conditions, including rickets and osteoporosis (2), as well as non-calcemic-related diseases such as diabetes (3), cardiovascular disease (4), autoimmune disease, and cancers of the colon, breast, and prostate (5). Prostate cancer (PCa) is of particular interest, since African American (AA) men are disproportionately affected by both PCa and risk of vitamin D deficiency (6-8). AAs not only present with PCa at a younger age, but they also have $50 \%$ higher incidence and twice the mortality compared with European American (EA) men (9). Skin pigmentation is the largest predictor of vitamin D deficiency in the USA, as UV-induced cutaneous synthesis of vitamin $\mathrm{D}$ is the primary source of the vitamin $\mathrm{D}$ prohormone and is inhibited by melanin (10). Consequently, $>90 \%$ of AA men are vitamin D insufficient by current standards (11), and $65 \%$ are deficient with serum levels below $20 \mathrm{ng} / \mathrm{ml}$ (12).

There is experimental, epidemiological, and clinical trial evidence to support chemopreventive and sometimes even anticancer activity of vitamin $\mathrm{D}$. In vitro and in vivo studies of the active hormone 1,25-dihydroxyvitamin $\mathrm{D}\left(1,25(\mathrm{OH})_{2} \mathrm{D}\right)$, as well as analogs, consistently demonstrate inhibition 
of cancer-related phenotypes (13-15). In genetic mouse models of PCa, such as the NKX3.1 model, vitamin D can delay the formation of preneoplastic lesions (16). Although epidemiologic studies on the relationship between PCa incidence and vitamin D serum concentration have produced mixed results, analyses restricted to aggressive or lethal cases have more consistently shown inverse associations (17-19). Interventional studies with vitamin D supplements have reported lower prostate-specific antigen levels (20), reduced number of positive biopsies (21), and decreased prostate proliferation markers (22). These studies are limited in their applicability to the racial disparity in PCa, since none included a diverse population of AA men. Also, it is not clear whether the positive results of these trials in PCa patients are mediated through systemic effects, such as immune regulation (23), or local effects of vitamin D within the tissues.

Serum concentration of the prohormone 25-hydroxyvitamin $\mathrm{D}(25(\mathrm{OH}) \mathrm{D})$ is the clinical indication of vitamin D status, and the Endocrine Society defines vitamin D deficiency as serum levels below $20 \mathrm{ng} /$ $\mathrm{ml}$, insufficiency between $21-29 \mathrm{ng} / \mathrm{ml}$, and replete status above $30 \mathrm{ng} / \mathrm{ml}$ (24). However, these cut points were formed solely in the context of bone health, and applicability to overall health and cancer prevention remain unclear. Additionally, whether serum and tissue levels of vitamin D correlate remains unclear, and there is only one comparative report on serum and intraprostatic levels of vitamin D (22). This pivotal study showed that oral supplementation with vitamin D can alter levels in the prostate tissue, but it also lacked diversity since all patients were Canadian men of European descent.

The effects of vitamin $\mathrm{D}$ are mediated by $1,25(\mathrm{OH})_{2} \mathrm{D}$, which is both the active hormone and high-affinity ligand for the vitamin D receptor (VDR), a classical nuclear hormone receptor transcription factor that regulates transcription via vitamin D response elements located throughout the genome (25-27). A direct readout of VDR activation is challenging to assess in patients and is dependent not only on ligand, but also on recruitment of coactivators and removal of corepressor binding (28). The circulating level of $1,25(\mathrm{OH})_{2} \mathrm{D}$ is under tight regulatory control by calcium and parathyroid hormone (29). 1 $\alpha$-hydroxylation of prohormone $25(\mathrm{OH}) \mathrm{D}$ to active hormone $1,25(\mathrm{OH})_{2} \mathrm{D}$ takes place in the kidney by the enzyme CYP27B1. There is also substantial evidence of extrarenal $1 \alpha$-hydroxylase activity in prostate cells (3032). Additionally, $1 \alpha$-hydroxylase activity has been reported to be reduced in primary cells derived from PCa tissue (33), suggesting a decrease in local levels of $1,25(\mathrm{OH})_{2} \mathrm{D}$ in tumors. Yet, in vivo evidence of prostatic CYP27B1 activity has not been demonstrated, and there remains only one report of $1,25(\mathrm{OH})_{2} \mathrm{D}$ in human prostate tissue (22).

Currently, multiple knowledge gaps exist regarding (i) the relationship between intraprostatic and serum vitamin D metabolites, (ii) the regulation of prostatic vitamin D metabolites, and (iii) intraprostatic levels of vitamin D metabolites in AA men. This knowledge is essential to understanding the proposed chemopreventive role of vitamin $\mathrm{D}$ in $\mathrm{PCa}$ and how it may contribute to the increased risk of aggressive $\mathrm{PCa}$ in AA men. In the present study, we describe the first evaluation of the serum and prostatic vitamin D axis in samples from a diverse cross sectional population of radical prostatectomy (RP) patients. Vitamin D metabolites were quantified in both the serum and prostate tissue. Expression of genes involved in vitamin D metabolism, transport, and VDR were measured in the prostatic epithelial tissues.

\section{Results}

AA PCa patients were vitamin D deficient in the serum and had higher levels of the active hormone in their prostate tissues. A diverse group of RP patients $(n=60)$ was assembled retrospectively to examine the serum-prostatic vitamin D axis (Figure 1A) by African ancestry (Table 1 and Figure 1B). Fresh frozen RP tissue, serum, and whole blood were used for analysis (Figure 1B). Of the patients, 32 self-identified as AA and 28 as EA. West African ancestry was determined by analysis of 105 ancestry informative markers (AIMs) (34) in DNA isolated from the whole blood and showed a heterogeneous population of EAs and a range of $53.0 \%-95.5 \%$ in the AA group (Figure 1C). One patient who self-identified as AA was reclassified as EA (2.2\% West African, 95.5\% European ancestry).

Vitamin D metabolites $25(\mathrm{OH}) \mathrm{D}$ and $1,25(\mathrm{OH})_{2} \mathrm{D}$ were measured in serum and frozen prostate tissue by ultra-high performance liquid chromatography coupled with tandem mass spectrometry (uHPLC-MSMS). The mean serum 25(OH)D concentration was lower in the AA group compared with the EA group (AA: $20 \mathrm{ng} / \mathrm{ml}, 95 \% \mathrm{CI}, 16-23 \mathrm{ng} / \mathrm{ml}$; EA: $33 \mathrm{ng} / \mathrm{ml}, 95 \% \mathrm{CI}, 28-37 \mathrm{ng} / \mathrm{ml} ; P<0.0001$ ) (Figure $2 \mathrm{~A}$ ). Serum levels of the active hormone $1,25(\mathrm{OH})_{2} \mathrm{D}$ did not differ between the 2 groups but did correlate with serum concentration of 25(OH)D in the EA group only (Spearman $\mathrm{r}=0.46 ; P=0.02$ ) (Figure $2, \mathrm{~A}$ and $\mathrm{B}$ ). 
$\mathbf{A}$
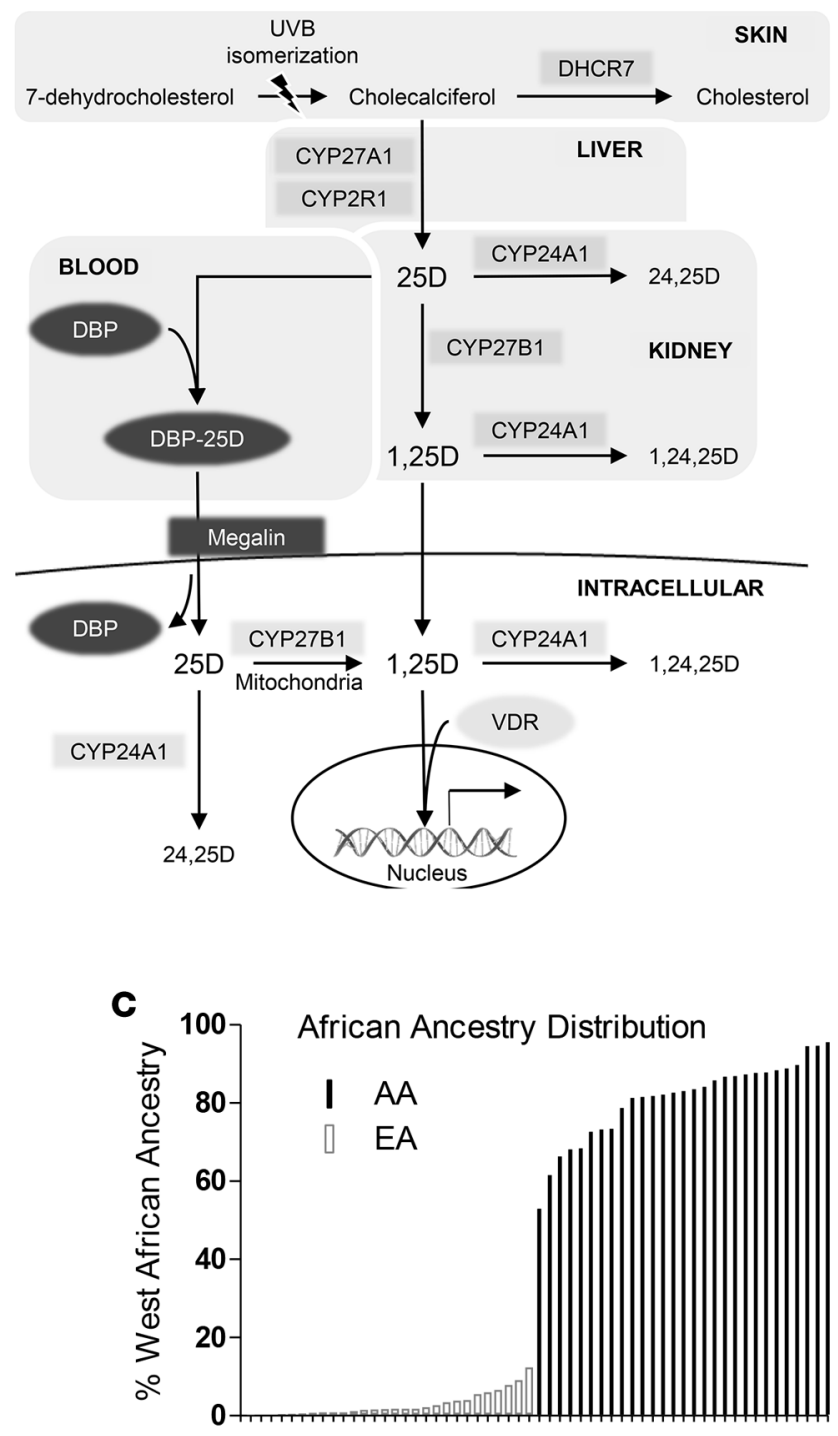

Study Population
B

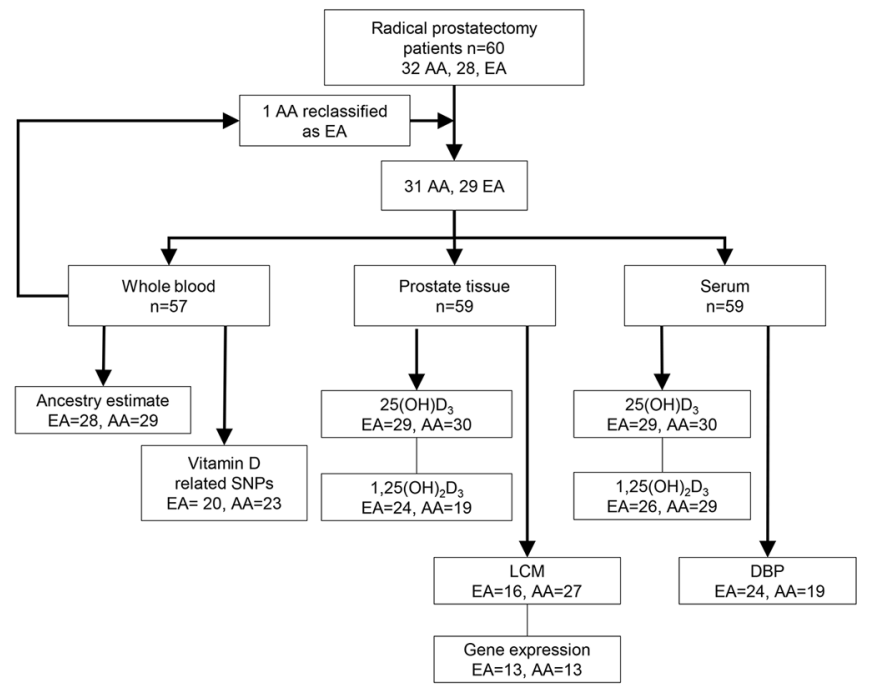

Extraction and measurement of $25(\mathrm{OH}) \mathrm{D}$ and $1,25(\mathrm{OH})_{2} \mathrm{D}$ by uHPLC-MS-MS in prostate tissue has not been previously reported and was thoroughly optimized for input and quality controls. Benign fresh frozen RP tissue was used for all patients. Vitamin D metabolite levels in the benign RP tissue did not differ from transurethral resection of the prostate samples that were used to optimize the assay (Supplemental Figure 1; supplemental material available online with this article; doi:10.1172/jci.insight.91054DS1). Similar to serum levels, prostatic 25(OH)D was lower in the AA group compared with EA group (AA: $11 \mathrm{ng} / \mathrm{g}$, 95\% CI, 8.4-15 ng/g; EA: $15 \mathrm{ng} / \mathrm{g}, 95 \% \mathrm{CI}, 12-18 \mathrm{ng} / \mathrm{g} ; P=0.04$ ) (Figure 2C). In contrast, the active hormone $1,25(\mathrm{OH})_{2} \mathrm{D}$ was significantly higher in the AA group's prostate tissue compared with the EA group's prostate tissue (AA: $34 \mathrm{pg} / \mathrm{g}, 95 \%$ CI, $27-40 \mathrm{pg} / \mathrm{g}$; EA: $23 \mathrm{pg} / \mathrm{g}, 95 \% \mathrm{CI}, 18-28 \mathrm{pg} / \mathrm{g} ; P=0.009$ ) (Figure $2 \mathrm{C}$ ). In all patients, $25(\mathrm{OH}) \mathrm{D}$ and $1,25(\mathrm{OH})_{2} \mathrm{D}$ were positively correlated in the prostate tissue (AA: $\mathrm{r}=0.49, P=0.08$; EA: $\mathrm{r}=0.50, P=0.01$ ) (Figure $2 \mathrm{D}$ ). Serum and tissue levels of vitamin $\mathrm{D}$ metabolites did not correlate with West African ancestry (data not shown). Vitamin $\mathrm{D}_{2}$ metabolites were also measured but were below the limit of detection in $88 \%$ of patients, and the contribution of $\mathrm{D}_{2}$ to total vitamin $\mathrm{D}$ was negligible in the 7 patients who had detectable levels (data not shown).

Most 25(OH)D in circulation ( $90 \%)$ is bound to the vitamin D binding protein (DBP) and is thought to affect the fraction available for conversion to $1,25(\mathrm{OH})_{2} \mathrm{D}(35)$. DBP was measured in serum using a polyclonal antibody ELISA, which has been demonstrated to mitigate bias caused by the presence of functional SNPs in DBP in AAs compared with the monoclonal assay $(36,37)$. Serum levels of DBP did 
Table 1. Population Characteristics

\begin{tabular}{|c|c|c|c|c|c|}
\hline & \multicolumn{2}{|c|}{ European American } & \multicolumn{2}{|c|}{ African American } & \multirow[b]{2}{*}{ P value $^{c}$} \\
\hline & $n^{\mathrm{A}}$ & Mean \pm SD or [range $]^{\mathrm{B}}$ & $n^{\mathrm{A}}$ & Mean \pm SD or [range] ${ }^{\mathrm{B}}$ & \\
\hline Age & 29 & $63.6 \pm 5.6$ & 31 & $61.5 \pm 7.2$ & 0.22 \\
\hline$\%$ Euro ancestry & 28 & 93.1 [79.1 to 99.2] & 29 & $14.3[1.6-45.1]$ & $<0.001$ \\
\hline$\%$ NatAmer ancestry & 28 & $4.0[0.5-14.9]$ & 29 & $4.8[0.8-11.3]$ & 0.45 \\
\hline PSA (ng/ml) & 25 & $6.8 \pm 3.1$ & 31 & $8.1 \pm 4.5$ & 0.22 \\
\hline Low UVR & 12 & & 18 & & 0.30 \\
\hline \multicolumn{6}{|l|}{ Season $^{\mathrm{D}}$ of surgery } \\
\hline High UVR & 17 & & 17 & & \\
\hline Low UVR & 12 & & 14 & & 0.80 \\
\hline \multicolumn{6}{|c|}{ Radical prostatectomy tissue } \\
\hline \multicolumn{6}{|l|}{ Stage $\mathrm{E}^{\mathrm{E}}$} \\
\hline 1 & 1 & & 1 & & \\
\hline IIA & 2 & & 2 & & \\
\hline IIB & 14 & & 16 & & \\
\hline III & 3 & & 8 & & 0.72 \\
\hline \multicolumn{6}{|l|}{ TURP tissue } \\
\hline $\mathrm{BPH}$ & 8 & & 3 & & 0.10 \\
\hline \multicolumn{6}{|l|}{ Biorepository } \\
\hline UIC & 9 & & 21 & & \\
\hline CHTN & 20 & & 10 & & 0.009 \\
\hline
\end{tabular}

AA, African American; EA, European American; UIC, University of Illinois at Chicago; CHTN, Cooperative Human Tissue Network; \%WA, percent West African; \%Euro, percent European ancestry; \%NatAmer, percent Native American ancestry; PSA, prostate specific antigen; TURP, transurethral resection of the prostate; BPH, benign prostatic hyperplasia; UVR, UV radiation. ${ }^{A}$ Cenotype data, Gleason score, or stage not available or not applicable to all individuals. ${ }^{B}$ Mean and \pm SD reported for age and PSA; range reported for ancestries. ${ }^{C} P<0.1,2$ sided student's $t$ test for age, ancestry, and PSA; 2-tailed Fisher's exact

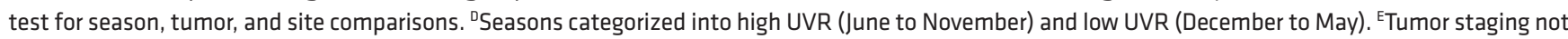
available for 2 patients (1 AA, $1 \mathrm{EA})$.

not differ between AAs and EAs (Figure 2E). Correlations of DBP with serum and prostate 25(OH)D levels were significantly positive for EAs, and they trended negative for AAs but did not reach significance (Figure 2, F and G).

Gene expression of VDR in benign prostate epithelium was higher in AAs compared with EAs. A homogenous population of benign prostate epithelium was collected from the frozen tissue by laser capture microdissection (LCM) for RNA isolation and gene expression analysis. Conditions for optimal RNA stability and recovery during LCM were previously described by our group $(38,39)$. Gene expression was quantified by whole transcriptome amplification followed by Affymetrix Human Gene 1.0 ST array as described by others for prostate tissues $(40,41)$. Thirteen patients from each group were selected for the gene expression analysis based on sufficient RNA input. Gene expression of $V D R$, the vitamin $\mathrm{D}$ metabolism genes - CYP27A1, CYP2R1, CYP27B1, CYP24A1, and DHCR7 - was determined (Figure 3, A-F). There was significantly higher expression of $V D R$ in the AA population (Figure $3 \mathrm{~A}$ ). Of the vitamin D metabolism enzymes, only $C Y P 2 R 1$ differed by ancestry group, with AAs having significantly lower expression (Figure 3B). $C Y P 2 R 1$ and $C Y P 27 B 1$ both correlated with percent West African ancestry in AAs, but in the negative and positive direction, respectively (Figure $3, \mathrm{~B}$ and $\mathrm{C}$ ).

Megalin protein is present in prostate epithelium, and gene expression of Megalin (LRP2) correlates with ancestry and prostatic vitamin $D$. Megalin, encoded by the gene $L R P 2$, is an abundantly present cell surface protein in the kidney that binds DBP to mediate internalization of $25(\mathrm{OH}) \mathrm{D}$ into the cytosol (42). 
A

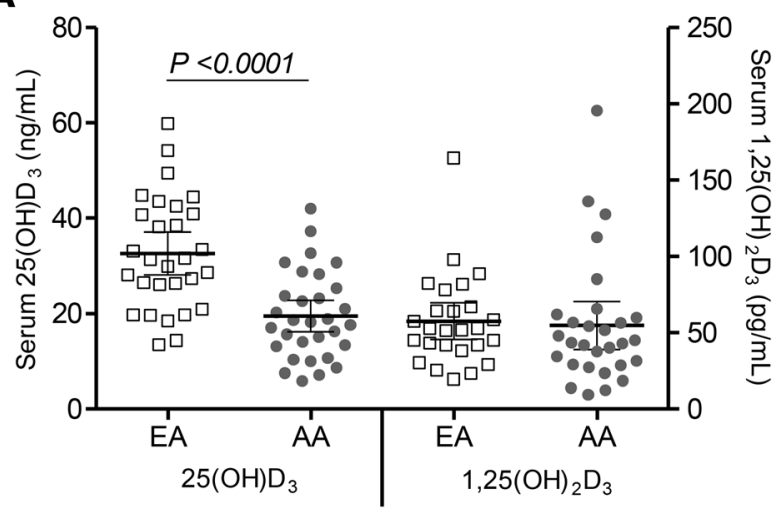

C

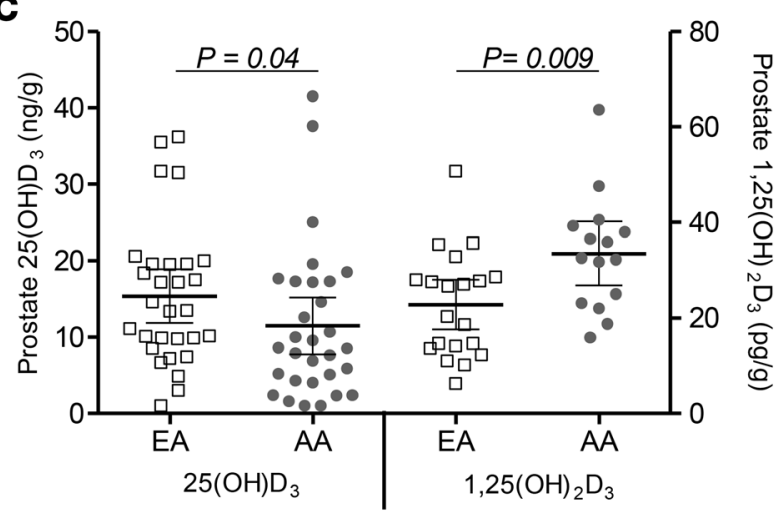

E

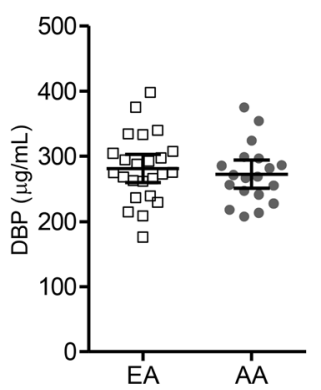

$\mathbf{F}$

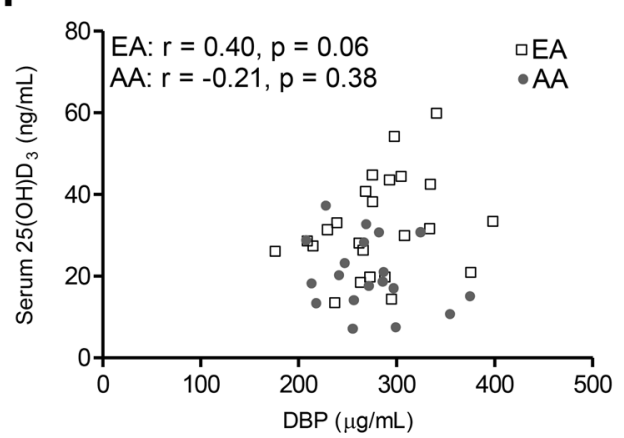

B

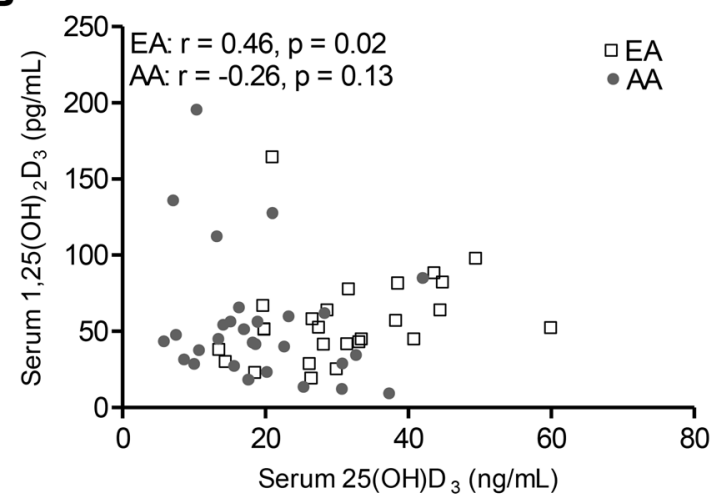

D

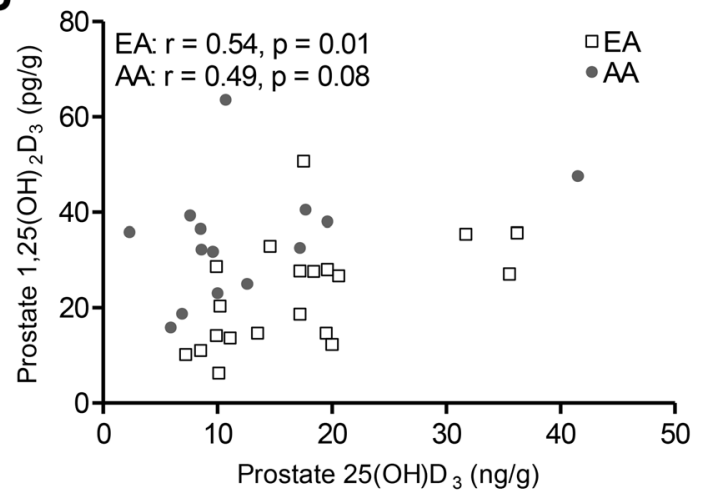

G

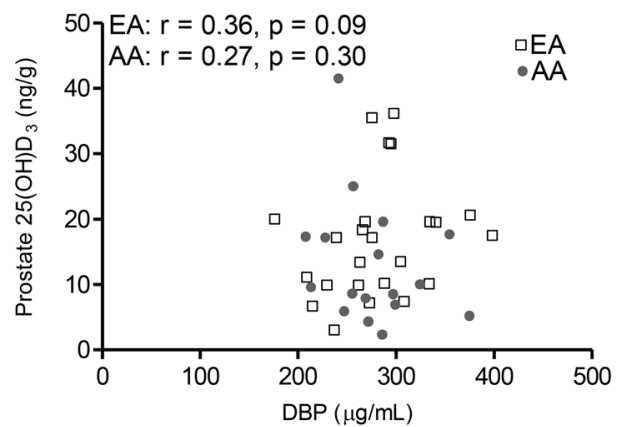

Figure 2. Radical prostatectomy patients of African ancestry had lower 25-hydroxyvitamin $D(25(\mathrm{OH}) \mathrm{D})$ in the serum but higher 1,25-dihydroxyvitamin $\mathbf{D}(\mathbf{1}, \mathbf{2 5}(\mathrm{OH}) \mathbf{D})$ in the prostate. (A) comparison of serum levels of $25(\mathrm{OH}) \mathrm{D}$ (European American [EA], $n=29$; African American $[\mathrm{AA}], n=30$ ) and 1,25(OH) D (EA, $n=26 ;^{2} A A, n=29$ ) measured by uHPLC-MS-MS between radical prostatectomy patients of AA and EA ancestry. (B) Correlation between vitamin $D{ }^{2}$ metabolites $25(\mathrm{OH}) \mathrm{D}$ and 1,25( $\mathrm{OH}) \mathrm{D}$ in the serum by ancestry $(\mathrm{EA}, n=26 ; \mathrm{AA}, n=29)$. (C) Comparison of prostate tissue (benign area) levels of $25(\mathrm{OH})$ $\mathrm{D}(\mathrm{EA}, n=29 ; \mathrm{AA}, n=30)$ and 1,25( $\mathrm{OH}) \mathrm{D}(\mathrm{EA}, n=24 ; \mathrm{AA}, n=19)$ measured by uHPLC-MS-MS. (D) Correlation between prostatic levels of 25(OH)D and $1,25(\mathrm{OH}) \mathrm{D}(\mathrm{EA}, n=24 ; \mathrm{AA}, n=19)$. (E) Serum levels of vitamin $\mathrm{D}$ binding protein (DBP) quantified by polyclonal antibody ELISA and correlation with $25(\mathrm{OH})$ $D$ levels in the $(\mathbf{F})$ serum and $(\mathbf{C})$ prostate tissue (EA, $n=24 ; A A, n=19$ ). $P<0.1$; differences by ancestry were determined by 2 -sided Wilcoxon signed-rank test and correlations determined by Spearman's rank coefficient.

The role of extrarenal Megalin and effect on tissue levels of 25(OH)D has not been reported. Given the essential function of Megalin in retaining 25(OH)D-DBP, LRP2 gene expression was examined in the prostate tissues. In our study, expression of $L R P 2$ was significantly positively correlated with West African ancestry; however, expression overall was not statistically different between the two populations (Figure 4A). In AAs only, LRP2 expression was significantly negatively correlated with tissue 25(OH) $\mathrm{D}$, and there was a similar negative trend with serum 25(OH)D (Figure 4B). Comparison of vitamin D metabolites between serum and prostate showed that $1,25(\mathrm{OH})_{2} \mathrm{D}$ did not correlate, suggesting active transport and local $1 \alpha$-hydroxylase activity by CYP27B1 rather than passive diffusion of $1,25(\mathrm{OH})_{2} \mathrm{D}$ 
A

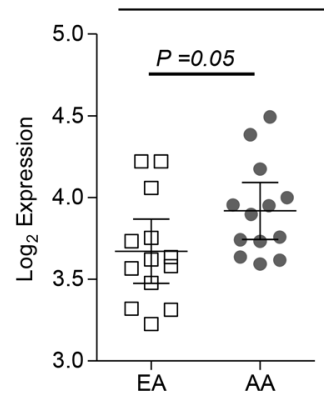

VDR

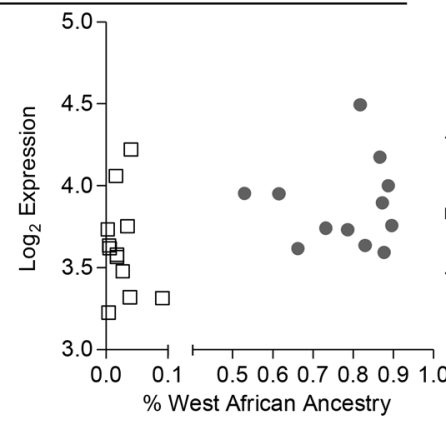

CYP27B1
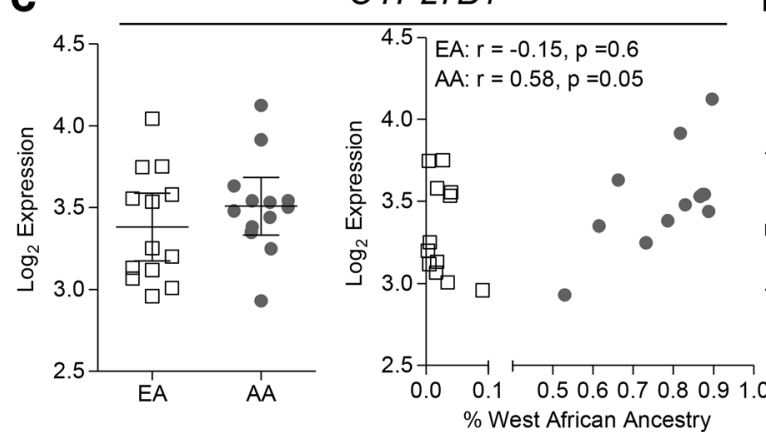

B

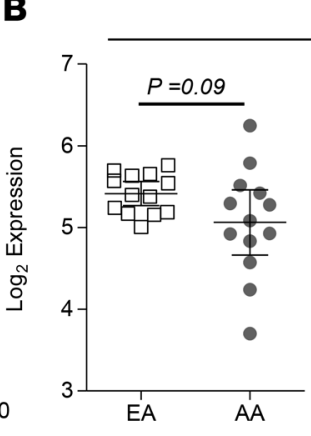

\section{CYP2R1}

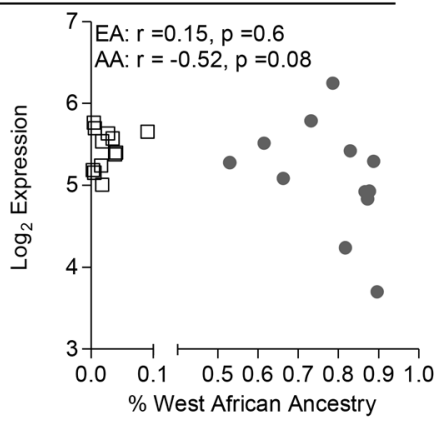

CYP27A1

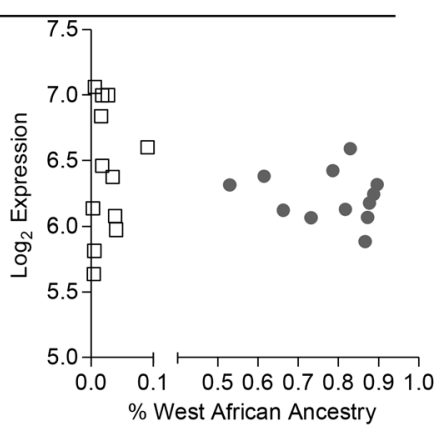

E

D

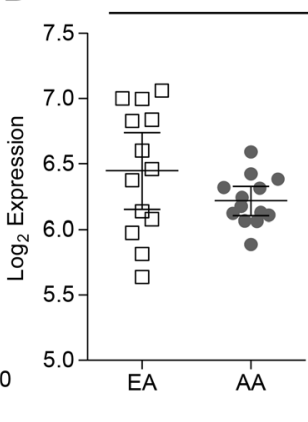

$\mathbf{F}$

DHCR7

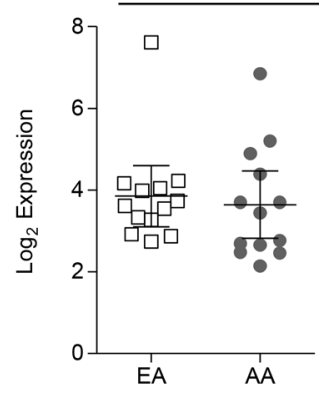

CYP24A1
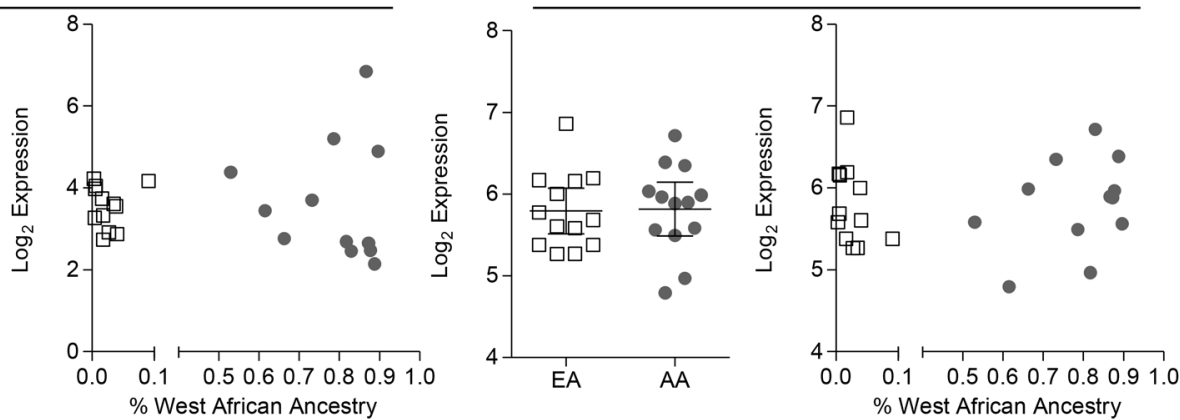

Figure 3. Expression of several vitamin D-related genes differ by ancestry and correlate to West African ancestry percentage. Affymetrix array expression (reported as log ) of selected vitamin D-related genes collected by laser capture microdissection from the benign epithelium of fresh frozen radical prostatectomy specimens. Gene expression by ancestry group and correlation to the percent West African ancestry for (A) VDR, (B) CYP2R1, (C) CYP27B1, (D) CYP27A1, (E) CYP24A1, (F) and DHCR7 (European American [EA], $n=13$; African American [AA], $n=13$ ). $P<0.1$; differences between ancestry determined by 2 -sided Wilcoxon signed-rank test, and correlations between gene expression and percent ancestry determined by Spearman's rank coefficient.

into the prostate (Figure 4C). Megalin protein was abundant in the prostate epithelium by immunofluorescent staining in both benign and PCa regions, and it was premembranous in some glands and cytosolic in others (Figure 4D).

SNPs in vitamin D-related genes associate with phenotypes. Patients were genotyped for 38 SNPs in 8 vitamin D metabolic and signaling pathway genes that were previously explored for associations with serum 25(OH)D levels in AA and EA men $(43,44)$. Several significant associations between SNPs and phenotypes were identified. SNP relationships to gene expression were analyzed for both self-regulation (cis-expression quantitative trait loci [cis-eQTL]) and regulation of other genes (trans-eQTL) (Table 2 and Supplemental Table 1). A missense variant in $G C$ (the coding gene for DBP), rs7041, was significantly associated with DBP levels in AAs $(P=0.006)$, and the minor allele $\mathrm{G}$ reduced DBP levels. SNPs in the DHCR7/NADSYN1 region were associated with several phenotypes, including prostatic $25(\mathrm{OH}) \mathrm{D}$ levels, and the minor allele $\mathrm{A}$ variant of rs382951 significantly reduced $D H C R 7$ expression levels $(\beta=-1.68, P=0.002)$.

Although the remaining associations were not statistically significant after correcting for multiple testing, we identified several interesting SNPs that may influence vitamin D metabolite levels and/or gene 
A

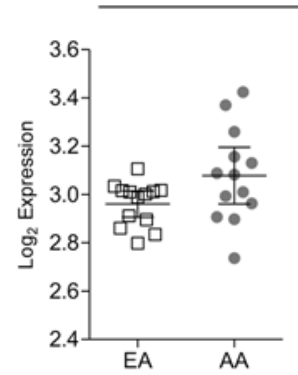

\section{LRP2}

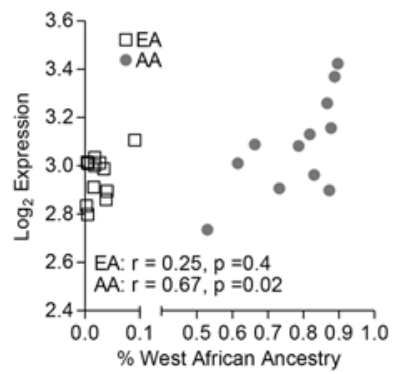

C
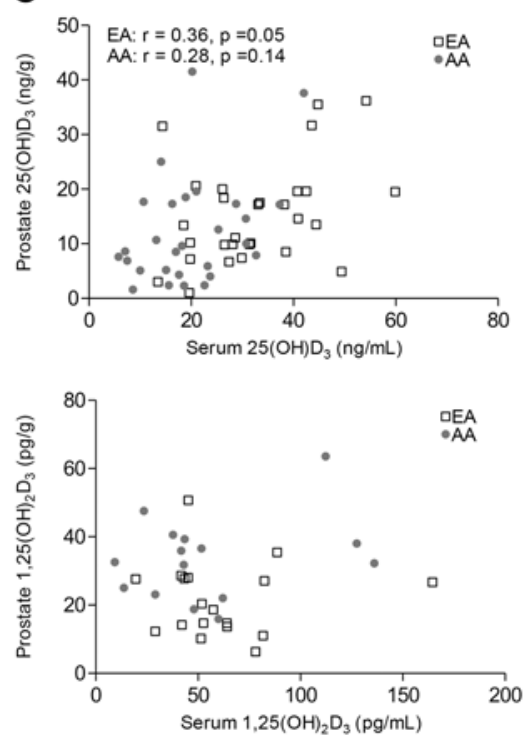

B
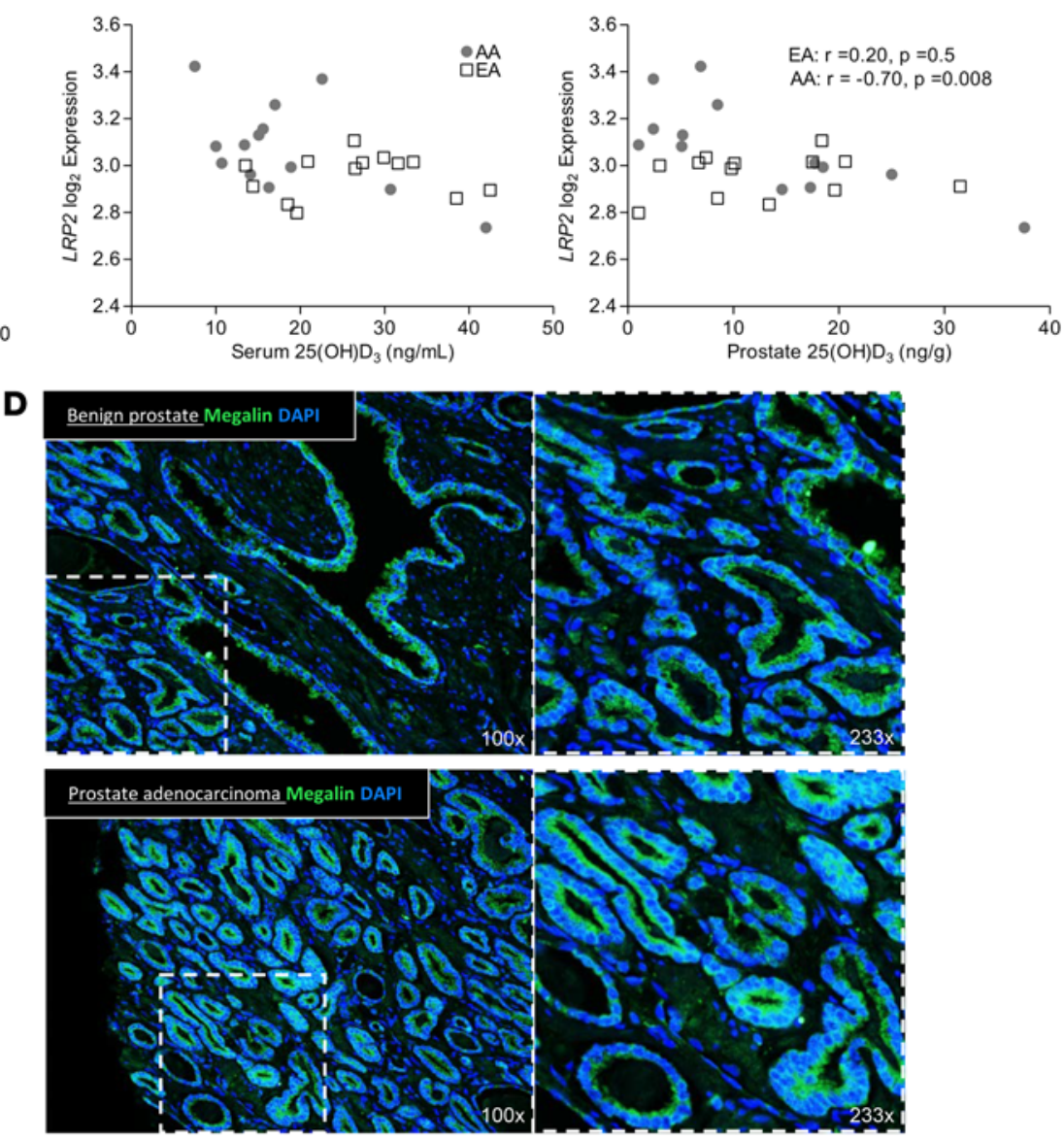

Figure 4. Megalin is present in prostate epithelium, and gene expression of Megalin (LRP2) correlates with ancestry and prostatic 25-hydroxyvitamin D. (A) Affymetrix array expression (reported as log ) of Megalin ( $L R P 2)$ in benign epithelium collected from fresh frozen radical prostatectomy specimens by laser capture microdissection (European American [EA], $n=13$; African American [AA], $n=13$ ). Comparison of gene expression by ancestry group and correlation to percent West African ancestry for $L R P 2 . P<0.1$; differences between ancestry determined by 2-sided Wilcoxon signed-rank test, and correlations determined by Spearman's rank. (B) Comparison by ancestry group of correlation between $\angle R P 2$ and $25(\mathrm{OH}) \mathrm{D}$ in the serum and prostate tissue. (C) Comparison by ancestry group of correlation between the vitamin D metabolites 25(OH)D (EA, $n=28 ; A A, n=28)$ and 1,25(OH) D (EA, $n=18$; AA, $n=15)$ between the serum and prostate tissue. (D) Benign and cancer areas of prostate tissue from a radical prostatectomy tissue specimen immunofluorescently stained for Megalin (green) and DAPI (blue) nuclear counterstain.

expression of vitamin D-related genes, given a larger sample size. Notably, among EAs only, 1 SNP in the CYP27B1 gene was associated with serum $1,25(\mathrm{OH})_{2} \mathrm{D}$ levels $(P=0.03)$ and another SNP in $C Y P 27 B 1$ was associated with $C Y P 27 B 1$ gene expression in AAs only $(P=0.03)$. Variants in the $V D R$ associated with expression of $C Y P 2 R 1$ in EAs $(P=0.03)$ and $C Y P 27 A 1$ in AAs $(P=0.011)$. The results of all tests with $P<$ 0.05 are shown in Supplemental Table 1.

\section{Discussion}

Our study presents the first report of vitamin D metabolite measurement in the prostate tissue from a diverse population of AA and EA men. Analysis of the entire prostatic vitamin D axis points to several potential compensatory mechanisms unique to the AA population.

Comparison of serum and prostate tissue vitamin D levels in AAs and EAs revealed both familiar and unexpected findings. AAs had significantly lower serum $25(\mathrm{OH}) \mathrm{D}$ than EAs, which corroborates epidemiologic reports in larger patient populations (44-46). Additionally, serum levels of $1,25(\mathrm{OH})_{2} \mathrm{D}$ did not differ by race, which was expected, given the tight regulatory control of the parathyroid gland on $1,25(\mathrm{OH})_{2} \mathrm{D}$ levels in circulation. Unexpectedly, AAs had higher levels of the active hormone $1,25(\mathrm{OH})_{2} \mathrm{D}$ in the prostate tissue, despite having lower levels of the circulating metabolite $25(\mathrm{OH}) \mathrm{D}$ in the serum. AAs also had 
Table 2. SNP associations between vitamin D binding protein and vitamin D metabolites levels or vitamin D pathway gene expression

\begin{tabular}{|c|c|c|c|c|c|c|c|c|c|}
\hline & SNP & Chromosome & Position ${ }^{A}$ & Gene & $M^{B}$ & MAF $^{c}$ & $n$ & $\beta$ & $\boldsymbol{P}$ \\
\hline \multicolumn{10}{|c|}{ Vitamin D Binding Protein } \\
\hline \multicolumn{10}{|l|}{ African Americans } \\
\hline \multicolumn{10}{|c|}{ Vitamin D Metabolites } \\
\hline \multicolumn{10}{|c|}{ European Americans } \\
\hline Serum 1,25(OH)D & rs10877012 & 12 & 58162085 & CYP27B1 & $\mathrm{T}$ & 0.34 & 19 & 0.142 & 0.03 \\
\hline \multicolumn{10}{|l|}{ African Americans } \\
\hline Prostatic $25(\mathrm{OH}) \mathrm{D}$ & rs12800438 & 11 & 71171003 & DHCR7/NADSYN1 & A & 0.48 & 21 & -0.291 & 0.007 \\
\hline \multicolumn{10}{|l|}{ trans-eQTL } \\
\hline \multicolumn{10}{|c|}{ European Americans } \\
\hline VDR & rs6022990 & 20 & 52775532 & CYP24A1 & G & 0.1 & 10 & 0.587 & 0.005 \\
\hline \multicolumn{10}{|l|}{ cis-eQTL } \\
\hline \multicolumn{10}{|l|}{ African Americans } \\
\hline CYP27B1 & rs4646537 & 12 & 58157281 & CYP27B1 & C & 0.2 & 10 & 0.359 & 0.027 \\
\hline DHCR7 & rs3829251 & 11 & 71194559 & DHCR7/NADSYN1 & A & 0.3 & 10 & -1.678 & $0.002^{D}$ \\
\hline
\end{tabular}

${ }^{A} \mathrm{CRCh} 37$, base-pair position. ${ }^{\mathrm{B}} \mathrm{MA}$, minor allele. ${ }^{\mathrm{C}} \mathrm{MAF}$, minor allele frequency. ${ }^{\mathrm{D}}$ Statistically significant based on $P$ value cutoff for testing association by linear regression Spearman correlation coefficient.

lower $25(\mathrm{OH}) \mathrm{D}$ in the prostate compared with EAs. Importantly, prostatic $25(\mathrm{OH}) \mathrm{D}$ and $1,25(\mathrm{OH})_{2} \mathrm{D}$ positivity correlated in both AAs and EAs, providing confidence in the uHPLC-MS-MS data and showing that intraprostatic $1,25(\mathrm{OH})_{2} \mathrm{D}$ levels are likely dependent on tissue $25(\mathrm{OH}) \mathrm{D}$ and not passive diffusion from the circulation, as previously thought (47). Despite this positive correlation, tissue metabolite concentrations diverged in AAs - lower 25(OH)D but higher 1,25(OH) $)_{2} \mathrm{D}$ - which was not observed in EAs and suggests a race-specific perturbation of vitamin $\mathrm{D}$ equilibrium in the prostate.

The intraprostatic metabolite data support the presence of $1 \alpha$-hydroxylase activity in the prostate. Circulating $1,25(\mathrm{OH})_{2} \mathrm{D}$ likely does not dictate tissue levels via passive diffusion, since serum $1,25(\mathrm{OH})_{2} \mathrm{D}$ levels did not correlate with prostatic $1,25(\mathrm{OH})_{2} \mathrm{D}$. Although local production of $1,25(\mathrm{OH})_{2} \mathrm{D}$ has been demonstrated in prostate cells in vitro, our data provides the first evidence in human tissue. Additionally, this revelation provides evidence that active hormone levels in the tissues do not mirror those in the circulation and suggests that "vitamin D status" is more complex than previously thought.

The lack of correlation between serum and tissue vitamin D levels also exposes a gap in the current understanding of vitamin D metabolite regulation in the tissues. Higher intraprostatic levels of the active hormone in AAs suggest compensatory differences in vitamin $\mathrm{D}$ delivery and metabolism that may be race specific. Nearly all $25(\mathrm{OH}) \mathrm{D}$ in circulation is bound to DBP and sequestered in the serum, thus preventing passive diffusion into the tissue. Racial differences in DBP levels have been postulated to alter the concentration of bioavailable vitamin D and, therefore, alter availability to the tissues (37). However, serum DBP was not different in our cross sectional group, which corroborates other recent studies (48) and associations between variants in $G C$ and DBP serum levels in our study emulate those reported by others $(37,49)$. This, in combination with our metabolite data, suggests serum DBP levels do not regulate tissue concentrations of vitamin D.

Circulating 25(OH)D bound to DBP can enter the cell via Megalin-mediated endocytosis, a process that is well understood in the kidney and functions to resorb $25(\mathrm{OH}) \mathrm{D}$ from the glomerular filtrate $(50$, 51). Expression of $L R P 2$ has been reported in the thyroid, kidney, brain, lung, breast, and adipose tissue. Here, we show the first report of Megalin protein expression in human prostate tissue. Previous reports of extrarenal DBP-Megalin-mediated uptake in the prostate are limited; just one in vitro study has reported 
Megalin protein in the immortalized and transformed LNCaP and PC-3 cell lines (52). We observed prominent membrane expression of Megalin protein in the prostate epithelium.

Not only was Megalin protein and RNA (LRP2) present in the prostate, but LRP2 expression had a strong positive correlation with West African ancestry in the AA patients. Skin pigmentation increases with West African ancestry and vitamin D synthesis depends on UV penetration of the skin; therefore, vitamin D status negatively correlates with West African ancestry (53). Megalin expression was also significantly correlated with prostate concentrations of $25(\mathrm{OH}) \mathrm{D}$ and trended negative with serum $25(\mathrm{OH}) \mathrm{D}$ in AAs only. Taken together, our data challenge the dogma of passive diffusion of bioavailable vitamin $\mathrm{D}$ and suggest that tissue levels of the hormone are not dependent on the unbound fraction of $25(\mathrm{OH}) \mathrm{D}$ in the serum, but instead point to a role for Megalin-mediated endocytosis of 25(OH)D-DBP in the prostate. Additionally, the absence of racial differences in serum DBP levels, the presence of Megalin in prostate epithelium, and the correlation of Megalin expression with tissue vitamin D metabolites in AAs point to a compensatory mechanism conserved by evolution to ensure adequate vitamin $\mathrm{D}$ in the prostate tissue. The free hormone hypothesis posits that DBP-bound $25(\mathrm{OH}) \mathrm{D}$ is not bioavailable (54), but our results suggest that Megalin expression in the prostate may be modulated to capture DBP-25(OH)D and challenges the assumption of vitamin D bioavailability.

Analysis of intraprostatic gene expression of $V D R$ and vitamin D metabolism enzymes also points to tissue compensation with evolutionary undertones. $V D R$ expression was significantly higher in AAs but may not equate to higher VDR activity for several reasons. First, there are known SNPs in VDR that may affect activity and, second, analysis of coregulatory proteins that interact with VDR on the DNA were not included in our study. Expression of CYP27B1 did not differ between AAs and EAs, but was positively correlated with West African ancestry and may lead to increased $1 \alpha$-hydroxylation as West African ancestry increases. The expression of $C Y P 2 R 1$, the enzyme that generates $25(\mathrm{OH}) \mathrm{D}$ from pre-vitamin $\mathrm{D}$, was present at significantly higher levels in EAs and also negatively correlated with West African ancestry. However, the biological significance of this observation remains unclear, as extrahepatic 25(OH)D synthesis has not been previously reported. Similarly, we observed an association between an SNP in DHCR7 that associated with gene expression of $D H C R 7$, suggesting cis-regulation via a functional SNP; however, extracutaneous roles for DHCR7 have not been previously described.

Measurement of vitamin $\mathrm{D}$ metabolites in the prostate tissue presents a new paradigm in vitamin $\mathrm{D}$ and PCa disparities research. Only one prior study has measured vitamin D metabolites in prostate tissue (22) in a population composed almost entirely of European ancestry and predominantly replete vitamin $\mathrm{D}$ status. In that study, $1,25(\mathrm{OH})_{2} \mathrm{D}$ was measured in both serum and tissue by enzyme immunoassay, whereas we utilized uHPLC-MS-MS to measure both $25(\mathrm{OH}) \mathrm{D}$ and $1,25(\mathrm{OH})_{2} \mathrm{D}$. Compared with standard HPLC-MS and radioimmunoassay, uHPLC-MS-MS has superior sensitivity and specificity, and it also enables differentiation between $\mathrm{D}_{2}$ and $\mathrm{D}_{3}$ isoforms.

The sum of our findings support the presence of a compensatory mechanism in AAs that ensures prostate levels of $1,25(\mathrm{OH})_{2} \mathrm{D}$ remain adequate, perhaps even higher, in the setting of low serum $25(\mathrm{OH})$ D. The discrepancy in serum 25(OH)D levels between AAs and EAs - with AAs being deficient - is central to the hypothesis that vitamin $\mathrm{D}$ is a chemopreventive agent and a biological contributor to the racial disparities in PCa. However, higher active hormone in the prostate tissue of AAs, association of CYP27B1 and $L R P 2$ expression with West African ancestry, association of $L R P 2$ expression with prostatic $25(\mathrm{OH}) \mathrm{D}$ in AAs, and increased $V D R$ expression in AAs challenge this notion and are highly suggestive of an evolutionary process of compensation.

Despite these findings, one must exercise caution before concluding that no vitamin $\mathrm{D}$ disparity exists. Our study had some limitations and leaves several potential key areas to be explored. For one, our study had an underrepresentation of vitamin D-deficient EAs, as well as replete AAs, which is needed to separate ancestry from deficiency. Second, our study does not rule out regulation of innate and adaptive immunity by vitamin D, which has been demonstrated to significantly influence inflammation-related pathways $(31,55)$ in AA men $(56)$. We examined gene expression solely in prostatic epithelium, which does not include immune cells or prostate stroma, both essential modulators of inflammatory gene signaling (31). The activity of VDR was not assessed by the endpoints of our study, and it is not only regulated by ligand but also transcriptional coregulators that were not included here (28).

In conclusion, this study provides insight into the distribution of vitamin $\mathrm{D}$ in the prostate, and the results challenge our previous assumptions. Our data show that the prostate can maintain levels of 
active vitamin $\mathrm{D}$ in the setting of serum deficiency, underscoring the essential role for this hormone in the prostate and perhaps other tissues. This reveals the paucity of knowledge about how vitamin $\mathrm{D}$ deficiency and/or ancestry alters the mechanisms and regulation of tissue levels of vitamin $\mathrm{D}$. It is premature at this point to speculate on the clinical implications of these findings in regards to vitamin $\mathrm{D}$ deficiency and prostate health.

\section{Methods}

\section{Patient biospecimens}

Fresh frozen prostate, whole blood, and serum were retrospectively collected from RP patients. Specimens from 60 patients were included for analysis: 30 from the UIC Hospital (Chicago, Illinois, USA) and 30 from the Cooperative Human Tissue Network Western Division at Vanderbilt University (Nashville, Tennessee, USA). Criteria for inclusion were self-declared race data, $>500 \mathrm{mg}$ of benign frozen prostatectomy specimen, serum, and whole blood. All patients had localized cancer without prior chemotherapy or hormonal therapy.

\section{Ancestry estimate}

DNA was isolated from $1 \mathrm{ml}$ of whole blood. One hundred and 5 AIMs were genotyped to assess ancestral admixture proportion (34). Agena Bioscience MassARRAY was used for genotyping. Ancestral admixture proportion, West African ancestry, European ancestry, and Native American ancestry were estimated using STRUCTURE 2.3 (57).

\section{LCM collection}

Prostate specimens were removed from liquid nitrogen storage and thawed to $-20^{\circ} \mathrm{C}$ in a cryostat prior to sectioning. RNase free conditions for LCM was carried out as previously described by our group (38). Briefly, 3 or more 10 micron cryosections per specimen were placed onto PEN membrane $4.0 \mu \mathrm{m}$ LCM slides from Leica Biosystems and stained with Toluidine blue in RNA and RNase free solutions for visualization under the microscope. An adjacent section was H\&E stained for markup by a board-certified pathologist. Only benign epithelium $>1 \mathrm{~cm}$ from cancer was used for this study. LCM was done for 1 hour only to prevent RNA degradation and resulted in 100-200 acini per specimen. Tissue was stored in lysis buffer (RNAqueous-Micro kit, Ambion) at $-80^{\circ} \mathrm{C}$ until ready for RNA isolation.

\section{RNA extraction and amplification}

Extraction and isolation of RNA from the LCM samples was completed using the RNAqueous-Micro kit, and the RNAqueous-Micro procedure for LCM protocol was followed with DNase treatment. Quantity and quality of RNA was assessed via NanoDrop ND-1000 (Thermo Scientific), and yields ranged from $99.6 \mathrm{ng} / \mu 1$ to $602.8 \mathrm{ng} / \mu 1$. For each sample, $10 \mathrm{ng}$ of RNA was used for whole transcriptome amplification using the Ovation PicoSL WTA System V2 (NuGEN) and purified with the DNA Clean \& Concentrator-25 kit (Zymo Research). Quantity and purity of cDNA was also assessed via NanoDrop.

\section{Gene expression analysis}

Amplified cDNA from 26 LCM patient samples (13 EA,13 AA) was biotin labeled using the Encore Biotin Module (NuGEN) and hybridized to GeneChip Human Gene 1.0 ST Arrays (Affymetrix). Use of microarray enabled optimal and accurate quantification of gene expression, given the limited nature of the LCM samples. Hybridization and chip scanning were completed by The Core Genomics Facility at the UIC using standard Affymetrix protocols. The samples were divided into two batches for labeling, hybridization, and scanning, and samples were evenly distributed across batches by race and collection site to mitigate any potential bias. Principal component analysis confirmed no batch effect was present. Microarray data from CEL files were read, background corrected, and normalized. Robust multi-array averages were generated using the Affy (58) and Oligo (59) packages from Bioconductor (https://www. bioconductor.org/) in $\mathrm{R}$ (https://cran.r-project.org/). The microarray data discussed in this publication have been deposited in NCBI's Gene Expression Omnibus (GEO) (60) and are accessible through GEO Series accession number GSE91037. 


\section{Histology}

A formalin-fixed and paraffin-embedded human tissue microarray containing 3 benign and 3 PCa cores was used to stain for Megalin protein. Sections of 5 microns were incubated with rabbit polyclonal antiLrp2/Megalin antibody (ab76969) diluted 1:100 (Abcam) and then incubated with secondary antibody AlexaFluor-488 goat anti-rabbit diluted 1:200 (Invitrogen), counterstained with DAPI, and imaged on the PerkinElmer Vectra 3.

\section{Vitamin D Metabolite Measurement}

Extraction. Samples were weighed and spiked with the internal standards d6-1,25(OH) $)_{2}, d 3-25(\mathrm{OH}) \mathrm{D}_{2}$, and $\mathrm{d} 3-25(\mathrm{OH}) \mathrm{D}_{3}$, then saponified with methonalic potassium hydroxide. Both deuterated and nondeutrated neat reagents were purchased from Sigma-Aldrich. After saponification for 2 hours, the samples were vortexed and extracted with methylene chloride. The organic layer was dried and reconstituted with hexane/methylene chloride, and both $25(\mathrm{OH}) \mathrm{D}$ and $1,25(\mathrm{OH})_{2} \mathrm{D}$ were isolated on a $0.5 \mathrm{~g}$ silica SPE column. The metabolites $1,25(\mathrm{OH})_{2} \mathrm{D}$ and $25(\mathrm{OH}) \mathrm{D}$ were eluted and then reconstituted into vitamin $\mathrm{D}$-stripped serum (DiaSorin).

$25(\mathrm{OH}) D$. From this point, the $25(\mathrm{OH}) \mathrm{D}$ was extracted via liquid-liquid extraction using hexanes alongside a serum-based standard curve with 972a serum (National Institute of Standards and Technology) serum 25(OH)D controls. The samples were reconstituted into LCMS-grade methanol and LCMS-high purity water both with $0.1 \%$ formic acid, and then injected onto an Agilent 1290 HPLC with an Agilent C18 Poroshell Column coupled to an Agilent 6460 Triple-quad mass spec with electrospray ionization source (ESI) in positive mode and analyzed using Masshunter software. The 25(OH)D measurements had a percent coefficient of variation of $8.6 \%$ for tissue and $6 \%$ for serum.

$1,25(\mathrm{OH})_{2} D$. The samples, standard curve, and $1,25(\mathrm{OH})_{2} \mathrm{D}$ QC calibrator (DiaSorin) were then extracted from the serum and serum reconstitution by acetonitrile protein precipitation, followed by SPE isolation using C-18OH DiaSorin columns. Samples were eluted and dried in a savant dryer. The $1,25(\mathrm{OH})_{2} \mathrm{D}$ fraction from the samples/standard curve/QC were derivatized using $100 \mu 1$ of $0.75 \mathrm{mg} / \mathrm{ml}$ PTAD in acetonitrile for 2 hours at room temperature. The samples were quenched with $50 \mu \mathrm{LCMS}$-grade water, loaded into LCMS vials, and injected onto an Agilent 1290 HPLC with an Agilent ZORBAX C18 Eclipse plus RRHD column coupled to an Agilent 6460 Triple-quad mass spec with ESI in positive mode and analyzed using Masshunter software. The $1,25(\mathrm{OH})_{2} \mathrm{D}$ assay had a percent coefficient of variation of $13.0 \%$ for tissue and $10.8 \%$ for serum.

\section{DBP measurement}

Serum levels of DBP were measured by the total Human Vitamin D Binding Protein polyclonal ELISA test kit (Genway Biotech Inc.) using $50 \mu \mathrm{l}$ of input, per manufacturer's instructions. This ELISA is a highly sensitive 2-site enzyme linked immunoassay (ELISA) for measuring DBP in human biological samples.

\section{Vitamin D-related SNPs}

SNPs, 38 in total, in 8 vitamin D metabolic and signaling pathway genes were genotyped as previously described (43). Agena Bioscience MassARRAY was used for genotyping. Four specific hypotheses were tested: (i) associations between GC (DBP alias) SNPs and DBP protein levels, (ii) associations between CYP27B1 SNPs and 25(OH)D and 1,25(OH) 2 D levels, (iii) associations between VDR SNPs and prostatic gene expression of CYP2R1, CYP24A1, CYP27A1, and CYP27B1 (trans-eQTL of VDR targets), and (iv) associations between SNPs and expression of the gene in which SNPs are located (cis-eQTL), in addition to associations of all the genotyped SNPs with DBP and vitamin D metabolites level and gene expression.

\section{Statistics}

The month of sample collection was recorded and plotted against each of the serum and tissue vitamin D metabolites (Supplemental Figure 2) and did not show a consistent difference in the UV-high months. Therefore, vitamin D metabolite levels were not adjusted for seasonality in the group comparisons. For comparison of metabolite levels between the AA and EA groups in both the serum and prostate tissue, a 2-sided Wilcoxon rank-sum test was used, as data did not follow a normal distribution. Spearman's rank coefficient, which compensates for nonparametric data and allows a nonlinear relationship, was calculated 
to quantify correlations between serum and prostate metabolites. Analysis of gene expression data also used a 2-sided Wilcoxon rank-sum test for comparisons between groups and the Spearman rank coefficient for correlations between gene expression and percent West African ancestry estimate. The mean and 95\% CI is reported for all data sets. $P<0.1$ was considered significant for all analyses. Linear regression was used to test the association between SNPs and DBP, as well as serum and prostatic vitamin D metabolite levels adjusted for age in EAs and age and West African ancestry for AAs. DBP and vitamin D metabolite levels were log-transformed to normalize the data. To test if genotyped SNPs are eQTL with vitamin D metabolic genes, we used $\log _{2}$-normalized gene expression levels as dependent variables in a linear regression model. The Spearman correlation coefficient is reported for all SNP statistical analysis and was performed using PLINK (61) and SPSS statistical software version 24.0 (IBM Corp.).

\section{Study Approval}

The samples were obtained from 2 deidentified biorepositories; Cooperative Human Tissue Network (CHTN) and UIC. The research was determined to not fit the definition of human subjects research by the UIC IRB (2013-0341).

\section{Author Contributions}

ZR contributed to LCM gene expression, statistical analyses, immunofluorescence, and preparation of the manuscript and figures. KB contributed to SNP analyses and interpretation. ES contributed to ancestry and SNP genotyping and analyses. RF contributed to patient sample preparation. AM performed all metabolite measurements. PHG provided the UIC patient specimens and statistical guidance in data analyses. RK contributed to genetic ancestry and SNP analyses and interpretation. LN provided study conception, organization among collaborators, funding, data analysis and interpretation, and preparation of the manuscript.

\section{Acknowledgments}

The research was funded by the Department of Defense Prostate Cancer Research Program Idea Award for Disparities Research PC121923 (LN and RK) and the NIH 1R01MD007105 (RK). Tissue samples were provided by the Cooperative Human Tissue Network, a NCI-supported resource, and as such, other investigators may have received samples from the same tissue specimens. We thank Vicky Macias and Andre Kajdacsy-Balla for assessment of pathology in the LCM slides. We thank Yachana Kataria, Erika Enk, and Ryan Deaton for assistance with the UIC patient samples. We thank Xiaofeng (Charles) Zhou for the use of the LCM microscrope.

Address correspondence to: Larisa Nonn, 840 South Wood Street, Room 130 CSN, MC 847, Chicago, Illinois 60612, USA. Phone: 312.996.0194; E-mail: 1nonn@uic.edu.

1. Lips P. Vitamin D physiology. Prog Biophys Mol Biol. 2006;92(1):4-8.

2. Holick MF. Sunlight and vitamin D for bone health and prevention of autoimmune diseases, cancers, and cardiovascular disease. Am J Clin Nutr. 2004;80(6 Supp1):1678S-1688S.

3. Herrmann M, et al. Serum 25-hydroxyvitamin D: a predictor of macrovascular and microvascular complications in patients with type 2 diabetes. Diabetes Care. 2015;38(3):521-528.

4. Dobnig $\mathrm{H}$, et al. Independent association of low serum 25-hydroxyvitamin d and 1,25-dihydroxyvitamin d levels with all-cause and cardiovascular mortality. Arch Intern Med. 2008;168(12):1340-1349.

5. Christakos S, Dhawan P, Verstuyf A, Verlinden L, Carmeliet G. Vitamin D: Metabolism, Molecular Mechanism of Action, and Pleiotropic Effects. Physiol Rev. 2016;96(1):365-408.

6. Taksler GB, Cutler DM, Giovannucci E, Smith MR, Keating NL. Ultraviolet index and racial differences in prostate cancer incidence and mortality. Cancer. 2013;119(17):3195-3203.

7. Holick MF, et al. Photosynthesis of previtamin D3 in human skin and the physiologic consequences. Science. 1980;210(4466):203-205.

8. Schwartz GG, Hulka BS. Is vitamin D deficiency a risk factor for prostate cancer? (Hypothesis). Anticancer Res. 1990;10(5A):1307-1311.

9. Siegel RL, Miller KD, Jemal A. Cancer statistics, 2016. CA Cancer J Clin. 2016;66(1):7-30.

10. Matsuoka LY, Wortsman J, Haddad JG, Kolm P, Hollis BW. Racial pigmentation and the cutaneous synthesis of vitamin D. Arch Dermatol. 1991;127(4):536-538.

11. Hollis BW. Circulating 25-hydroxyvitamin D levels indicative of vitamin D sufficiency: implications for establishing a new effective dietary intake recommendation for vitamin D. J Nutr. 2005;135(2):317-322. 
12. Ginde AA, Liu MC, Camargo CA. Demographic differences and trends of vitamin D insufficiency in the US population, 19882004. Arch Intern Med. 2009;169(6):626-632.

13. Krishnan AV, Trump DL, Johnson CS, Feldman D. The role of vitamin D in cancer prevention and treatment. Endocrinol Metab Clin North Am. 2010;39(2):401-18, table of contents.

14. Schwartz GG, Wang MH, Zang M, Singh RK, Siegal GP. 1 alpha,25-Dihydroxyvitamin D (calcitriol) inhibits the invasiveness of human prostate cancer cells. Cancer Epidemiol Biomarkers Prev. 1997;6(9):727-732.

15. van den Bemd GJ, Pols HA, van Leeuwen JP. Anti-tumor effects of 1,25-dihydroxyvitamin D3 and vitamin D analogs. Curr Pharm Des. 2000;6(7):717-732.

16. Banach-Petrosky W, et al. Vitamin D inhibits the formation of prostatic intraepithelial neoplasia in Nkx3.1;Pten mutant mice. Clin Cancer Res. 2006;12(19):5895-5901.

17. Steck SE, et al. Association between Plasma 25-Hydroxyvitamin D, Ancestry and Aggressive Prostate Cancer among African Americans and European Americans in PCaP. PLoS One. 2015;10(4):e0125151.

18. Shui IM, et al. Circulating vitamin D, vitamin D-related genetic variation, and risk of fatal prostate cancer in the National Cancer Institute Breast and Prostate Cancer Cohort Consortium. Cancer. 2015;121(12):1949-1956.

19. Murphy AB, et al. Vitamin D deficiency predicts prostate biopsy outcomes. Clin Cancer Res. 2014;20(9):2289-2299.

20. Woo TC, Choo R, Jamieson M, Chander S, Vieth R. Pilot study: potential role of vitamin D (Cholecalciferol) in patients with PSA relapse after definitive therapy. Nutr Cancer. 2005;51(1):32-36.

21. Hollis BW, Marshall DT, Savage SJ, Garrett-Mayer E, Kindy MS, Gattoni-Celli S. Vitamin D3 supplementation, low-risk prostate cancer, and health disparities. J Steroid Biochem Mol Biol. 2013;136:233-237.

22. Wagner $\mathrm{D}$, et al. Randomized clinical trial of vitamin $\mathrm{D} 3$ doses on prostatic vitamin D metabolite levels and ki67 labeling in prostate cancer patients. J Clin Endocrinol Metab. 2013;98(4):1498-1507.

23. Hewison M. Vitamin D and immune function: an overview. Proc Nutr Soc. 2012;71(1):50-61.

24. Holick MF, et al. Evaluation, treatment, and prevention of vitamin D deficiency: an Endocrine Society clinical practice guideline. J Clin Endocrinol Metab. 2011;96(7):1911-1930.

25. Skowronski RJ, Peehl DM, Feldman D. Vitamin D and prostate cancer: 1,25 dihydroxyvitamin D3 receptors and actions in human prostate cancer cell lines. Endocrinology. 1993;132(5):1952-1960.

26. Haussler MR, Jurutka PW, Mizwicki M, Norman AW. Vitamin D receptor (VDR)-mediated actions of $1 \alpha, 25(\mathrm{OH})_{2}$ vitamin $\mathrm{D}_{3}$ : genomic and non-genomic mechanisms. Best Pract Res Clin Endocrinol Metab. 2011;25(4):543-559.

27. Pike JW, Meyer MB. Fundamentals of vitamin D hormone-regulated gene expression. J Steroid Biochem Mol Biol. 2014;144 Pt A:5-11.

28. Haussler MR, et al. Vitamin D receptor: molecular signaling and actions of nutritional ligands in disease prevention. Nutr Rev. 2008;66(10 Suppl 2):S98-112.

29. Bikle DD. Vitamin D metabolism, mechanism of action, and clinical applications. Chem Biol. 2014;21(3):319-329.

30. Zehnder D, et al. Extrarenal expression of 25-hydroxyvitamin d(3)-1 alpha-hydroxylase. J Clin Endocrinol Metab. 2001;86(2):888-894.

31. Giangreco AA, et al. Differential expression and regulation of vitamin D hydroxylases and inflammatory genes in prostate stroma and epithelium by 1,25-dihydroxyvitamin D in men with prostate cancer and an in vitro model. J Steroid Biochem Mol Biol. 2015;148:156-165.

32. Schwartz GG, Whitlatch LW, Chen TC, Lokeshwar BL, Holick MF. Human prostate cells synthesize 1,25-dihydroxyvitamin D3 from 25-hydroxyvitamin D3. Cancer Epidemiol Biomarkers Prev. 1998;7(5):391-395.

33. Hsu JY, Feldman D, McNeal JE, Peehl DM. Reduced 1alpha-hydroxylase activity in human prostate cancer cells correlates with decreased susceptibility to 25-hydroxyvitamin D3-induced growth inhibition. Cancer Res. 2001;61(7):2852-2856.

34. Giri VN, et al. Race, genetic West African ancestry, and prostate cancer prediction by prostate-specific antigen in prospectively screened high-risk men. Cancer Prev Res (Phila). 2009;2(3):244-250

35. Bikle DD, Gee E, Halloran B, Kowalski MA, Ryzen E, Haddad JG. Assessment of the free fraction of 25-hydroxyvitamin D in serum and its regulation by albumin and the vitamin D-binding protein. J Clin Endocrinol Metab. 1986;63(4):954-959.

36. Nielson CM, et al. Free 25-Hydroxyvitamin D: Impact of Vitamin D Binding Protein Assays on Racial-Genotypic Associations J Clin Endocrinol Metab. 2016;101(5):2226-2234

37. Powe CE, et al. Vitamin D-binding protein and vitamin D status of black Americans and white Americans. N Engl J Med. 2013;369(21):1991-2000.

38. Lugli G, et al. Laser-capture Microdissection of Human Prostatic Epithelium for RNA Analysis. J Vis Exp. 2015;(105):53405.

39. Nonn L, Vaishnav A, Gallagher L, Gann PH. mRNA and micro-RNA expression analysis in laser-capture microdissected prostate biopsies: valuable tool for risk assessment and prevention trials. Exp Mol Pathol. 2010;88(1):45-51.

40. Erho N, et al. Discovery and validation of a prostate cancer genomic classifier that predicts early metastasis following radical prostatectomy. PLoS One. 2013;8(6):e66855.

41. Karnes RJ, et al. Validation of a genomic classifier that predicts metastasis following radical prostatectomy in an at risk patient population. J Urol. 2013;190(6):2047-2053

42. Christensen EI, Birn H. Megalin and cubilin: multifunctional endocytic receptors. Nat Rev Mol Cell Biol. 2002;3(4):256-266.

43. Batai $\mathrm{K}$, et al. Common vitamin D pathway gene variants reveal contrasting effects on serum vitamin D levels in African Americans and European Americans. Hum Genet. 2014;133(11):1395-1405.

44. Ahn J, et al. Vitamin D-related genes, serum vitamin D concentrations and prostate cancer risk. Carcinogenesis. 2009;30(5):769776

45. Murphy AB, et al. Predictors of serum vitamin D levels in African American and European American men in Chicago. Am J Mens Health. 2012;6(5):420-426.

46. Schenk JM, et al. Serum 25-hydroxyvitamin D concentrations and risk of prostate cancer: results from the Prostate Cancer Prevention Trial. Cancer Epidemiol Biomarkers Prev. 2014;23(8):1484-1493.

47. Chun RF, Peercy BE, Orwoll ES, Nielson CM, Adams JS, Hewison M. Vitamin D and DBP: the free hormone hypothesis revisited. J Steroid Biochem Mol Biol. 2014;144 Pt A:132-137. 
48. Nielson CM, et al. Role of Assay Type in Determining Free 25-Hydroxyvitamin D Levels in Diverse Populations. $N$ Engl J Med 2016;374(17):1695-1696.

49. Moy KA, et al. Genome-wide association study of circulating vitamin D-binding protein. Am J Clin Nutr. 2014;99(6):1424-1431.

50. Hilpert J, et al. Expression profiling confirms the role of endocytic receptor megalin in renal vitamin D3 metabolism. Kidney Int 2002;62(5):1672-1681.

51. Perez Bay AE, et al. The fast-recycling receptor Megalin defines the apical recycling pathway of epithelial cells. Nat Commun. 2016;7:11550.

52. Ternes SB, Rowling MJ. Vitamin D transport proteins megalin and disabled-2 are expressed in prostate and colon epithelial cells and are induced and activated by all-trans-retinoic acid. Nutr Cancer. 2013;65(6):900-907.

53. Signorello LB, et al. Blood vitamin d levels in relation to genetic estimation of African ancestry. Cancer Epidemiol Biomarkers Prev. 2010;19(9):2325-2331.

54. Mendel CM. The free hormone hypothesis: a physiologically based mathematical model. Endocr Rev. 1989;10(3):232-274.

55. Batai K, Murphy AB, Nonn L, Kittles RA. Vitamin D and Immune Response: Implications for Prostate Cancer in African Americans. Front Immunol. 2016;7:53.

56. Hardiman G, et al. Systems analysis of the prostate transcriptome in African-American men compared with European-American men. Pharmacogenomics. 2016;17(10):1129-1143.

57. Falush D, Stephens M, Pritchard JK. Inference of population structure using multilocus genotype data: linked loci and correlated allele frequencies. Genetics. 2003;164(4):1567-1587.

58. Gautier L, Cope L, Bolstad BM, Irizarry RA. affy--analysis of Affymetrix GeneChip data at the probe level. Bioinformatics. 2004;20(3):307-315.

59. Carvalho BS, Irizarry RA. A framework for oligonucleotide microarray preprocessing. Bioinformatics. 2010;26(19):2363-2367.

60. Barrett T, et al. NCBI GEO: archive for functional genomics data sets--update. Nucleic Acids Res. 2013;41(Database issue):D991-D995

61. Purcell S, et al. PLINK: a tool set for whole-genome association and population-based linkage analyses. Am J Hum Genet. 2007;81(3):559-575 